\section{Growth and Water Relations of Kentucky Coffee Tree in Protective Shelters during Establishment}

\author{
Roger Kjelgren ${ }^{1}$ \\ Department of Plants and Soils, Southern Illinois University, Carbondale, \\ IL 62901
}

Additional index words. stomatal conductance, water potential, Gymnocladus dioica, tree shelters, transpiration

\begin{abstract}
Growth and water relations of Kentucky coffee tree [Gymnocladus dioica (L.) K. Koch] whips in translucent tubelike shelters were investigated. In a container study, 1.2m-high shelters were placed over whips following transplanting, then diurnal microclimate, water relations, and water use were measured. Shelter air temperature and vapor pressure were substantially higher, and solar radiation was $\mathbf{7 0 \%}$ lower, than ambient conditions. Sheltered trees responded with nearly three-times higher stomatrd conductance than nonsheltered trees. However, due to substantially lower boundary layer conductance created by the shelter, normalized water use was 40910 lower. In a second experiment, same-sized shelters were placed on whips following spring transplanting in the field. Predawn and midday leaf water potentials and midday stomatal conductance (g,) were monitored periodically through the season, and growth was measured in late summer. Midday $\mathbf{g}_{\mathrm{s}}$ was also much higher in field-grown trees with shelters than in those without. Sheltered trees in the field had four times greater terminal shoot elongation but $40 \%$ less stem diameter growth. Attenuated radiation in the shelters and lower specific leaf area of sheltered trees indicated shade acclimation. Shelters can improve height and reduce water loss during establishment in a field nursery, but they do not allow for sufficient trunk growth.
\end{abstract}

Tree shelters, developed initially to reduce herbivory on newly planted tree seedlings, have been shown to improve elongation (Potter, 1988). Apparently, this is due to greenhouse-like conditions in the shelter, where interior temperatures and humidities are higher but transpiration rates from tree seedlings are sometimes lower (Burger et al., 1992). Tree shelters may benefit nursery field production by enhancing growth, reducing production time, and reducing water stress following field transplanting where routine irrigation is not available. Not all species perform equally well in shelters (Potter, 1988), and physiological responses to shelter microclimate are not completely known. Information on gas exchange and leaf temperature $\left(\mathrm{t}_{1}\right)$ may provide insight as to why some species do not grow well inside shelters and suggest possible management options. The objectives of this study were to investigate microclimate changes and tree physiological response and growth in shelters for a nursery setting.

\footnotetext{
Received for publication 6 July 1993. Accepted for publication 4 Feb. 1994. The cost of publishing this paper was defrayed in part by the payment of page charges. Under postal regulations, this paper therefore must be hereby marked advertisement solely to indicate this fact.

${ }^{1}$ Assistant Professor. Current address: Dept. of Plants, Soils, and Biometeorology, Utah State Univ., Logan, UT 84322 .
}

Dawn-to-dusk water relations were studied on both dates. Stomatal conductance $\left(\mathrm{g}_{\mathrm{s}}\right)$ and $t_{1}$ were measured with a steady-state porometer (model 1600; LI-COR, Lincoln, Neb.) and infrared-thermometer (model 3100; Everest Interscience, Fullerton, Calif.), respectively. Conductance and $\mathrm{t}_{1}$ were measured through a small window cut into the south side of the shelter at mid-canopy level. After the window was opened, a single $t_{1}$ measurement that integrated foliage temperature over the exposed area was taken immediately $0.2 \mathrm{~m}$ from the window. This test was followed quickly by $\mathrm{g}_{\mathrm{s}}$ measurements on three illuminated leaves per tree. Measurements were taken as rapidly as possible to avoid confounding effects of outside conditions on $t_{1}$ and $g_{s}$. The window was taped between measurements to prevent air movement into the shelter. Insufficient crown density, which permitted transmission of background radiation, precluded leaf temperature measurement of trees without shelters. After 15 Aug., foliage was harvested from each tree, and leaf area was measured with a leaf area meter (model 3 100; LI-COR). Dawn-to-dusk wet-bulb and air temperatures $\left(\mathrm{t}_{\mathrm{a}}\right)$ also were measured by drawing shelter atmosphere into a fan-aspirated thermocouple psychrometer (model 90023C; Atkins Technical, Gainesville, Fla.) through a closed cylinder inserted through a small hole into the shelter. Wind speed in the shelters also was measured periodically through the day with a hot wire anemometer (series 490; Kurtz Instruments, Carmel Valley, Calif.). The hole was sealed between measurements.

Field experiment. Kentucky coffee tree whips were planted in a Hosmer silt loam (fine-silty, mixed-mesic, Typic Fragiudalf) in mid-Mar. 1991. The design was a randomized complete block plus or minus shelters with 10 single-tree replications. Same-sized shelters were placed over treatment seedlings, and the base was inserted 30 to $40 \mathrm{~mm}$ into the ground. Shelters were then firmly attached to supporting stakes placed on the north side of the tube. These trees received no supplemental irrigation, and the surrounding soil surface was clean-cultivated through the season. Global shortwave radiation and air temperature in the shelters were measured over 2 days in late Aug. 1991. A horizontally leveled pyranometer (model 200SA; LI-COR) was fixedto the wall immediately above the canopy inside one representative shelter. Because the limited spectral response of this pyranometer is calibrated to the daylight spectrum under full sun, values were corrected later to a star pyranometer (model 3020; Weathertronics-Qualimetrics, Sacramento, Calif.) with a broader spectral response in the blue and infrared wavebands. A thermistor also was inserted $40 \mathrm{~mm}$ into the shelter at canopy level to measure shelter air temperature and another thermistor was positioned outside the tube within a radiation shield $2 \mathrm{~m}$ high to measure ambient temperature. The next day these measurements were repeated in a shelter without a tree to determine the effect of transpiration on air temperature in the shelter. Signal-wire holes were sealed to prevent air moving into the shelter. Output was logged 


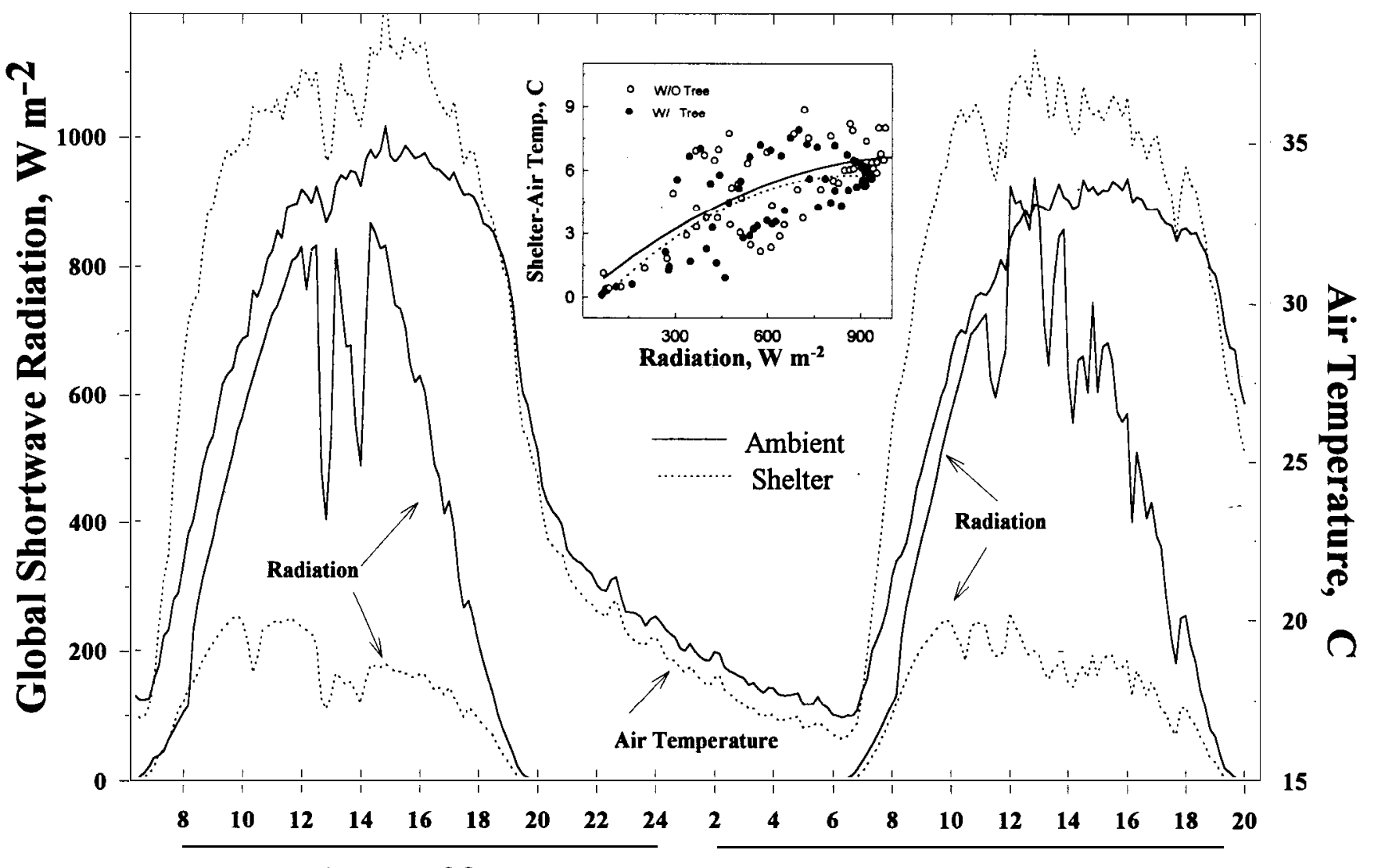

August 23

\section{Hour}

Fig. 1. Global shortwave radiation and air temperature inside tree shelters (- - - -) and ambient (-) for field-grown Kentucky coffee on 23 to 24 Aug. 1991. Inset: Shelter minus ambient air temperature in response to shortwave radiation with and without trees. Data fitted to second-order curves, where shelter minus ambient $\mathrm{t}_{\mathrm{a}}$ for shelter without a tree $(-)=0.0917+0.0121 \mathrm{x}-0.0001 \mathrm{x}^{2}, r^{2}=0.51$; shelter minus ambient $\mathrm{t}_{\mathrm{a}}$ for shelter with a tree $(-)=-1.02+0.0155 \mathrm{x}$ $-0.512 \mathrm{x}^{2}, r^{2}=0.52$.

as 30-min averages with an analog to digital converter (model 1000; LI-COR).

On 2 Aug., after 23 days without rain, predawn and midday $\psi$ and midday $g_{s}$ and $t_{1}$ were measured on five trees of each treatment. All trees had sufficiently dense crowns for measurement with the infrared thermometer. Trunk growth increment was calculated as the difference between initial diameter measured at ground level before budbreak and a final measurement. taken in early September. Current-season growth of the terminal shoot of each tree also was measured. All foliage was harvested, and leaf area was measured with a leaf area meter (model LI-3000; LI-COR) in late September. Then leaves were dried and weighed.

Data analysis. Specific leaf area was calculated as the ratio of leaf area to leaf weight from the trees in the field experiment. Boundary layer conductance to water vapor was calculated from the average daily water relations and meteorologic data for the container study on 31 July.

$\mathrm{T} \times \mathrm{LA}^{-1}=\mathrm{VDD} \times\left(\mathrm{g}_{\mathrm{s}}+\mathrm{g}_{\mathrm{b}}\right)$

where $\mathrm{g}_{\mathrm{bl}}=$ average daily boundary layer conductance $\left(\mathrm{m} \cdot \mathrm{s}^{-1}\right), \mathrm{T}=$ actual tree transpiration $\left(\mathrm{m}^{3} \cdot \mathrm{day}^{-1}\right) . \mathrm{LA}=$ leaf area $\left(\mathrm{m}^{2}\right), \mathrm{VDD}=$ leaf-air average daily vapor density deficit $\left(\mathrm{g} \cdot \mathrm{m}^{-3}\right.$, from leaf, wet-, and dry-bulb temperatures), and $g_{s}=$ average daily stomatal conductance converted from molar $\left(\mathrm{mmol} \cdot \mathrm{m}^{-2} \cdot \mathrm{s}^{-1}\right)$ to volumetric units $\left(\mathrm{m} \cdot \mathrm{s}^{-1}\right)$ with $\mathrm{t}_{1}$ using a gas law algorithm (McDermitt, 1990). Equation [1] was rearranged to solve for $g_{b}$, and then $g_{b}$ was converted back to molar units.

$\mathrm{g}_{\mathrm{bl}}=\left(\mathrm{VDD}^{-1} \times \mathrm{LA}^{-1} \times \mathrm{T}\right)-\mathrm{g}_{\mathrm{s}}$

Dawn-to-dusk $g_{s}, t$, air temperature, and vapor pressure deficit (VPD) inside and outside shelters were plotted against time. Differences in onetime water relations and growth measurements were tested for significance with t tests.

\section{Results and Discussion}

The microclimate, measured over 2 days, in shelters with field-grown trees was substantially different than ambient conditions (Fig. 1). Shelters reduced gobal shortwave radiation to $<25 \%$ of full sun, and rapid changes due to cloud cover were substantially attenuated. Midday shelter $\mathrm{t}_{\mathrm{a}}$ was from 3 to $5 \mathrm{C}$ higher than ambient-a slightly larger difference than reported by Burger et al. (1992). Shelter and ambient $\mathrm{t}$ rapidly converged after sundown, and through the night, it was $\approx 2 \mathrm{C}$ cooler in shelters. Shelter $t$ increased with shortwave radiation relative to ambient $\mathrm{t}_{\mathrm{a}}$ (Fig. 1 , inset), but at radiation levels $>900 \mathrm{~W} \cdot \mathrm{m}^{-2}, \mathrm{t}_{\mathrm{a}}$ in shelters without transpiring foliage was 1 to $2 \mathrm{C}$ higher than those with trees. In the container experiment, shelter $\mathrm{t}_{\mathrm{a}}$ was 2 to $6 \mathrm{C}$ higher than ambient on two dates (Fig. 2). Despite higher $\mathrm{t}_{\mathrm{a}}$, shelter VPD only slightly exceeded $1 \mathrm{kpa}$, compared to 2.5 to $3.0 \mathrm{kPa}$ in the ambient air, indicating substantially more water vapor in the shelter air.

In the container experiment, warm and moist conditions in the shelters substantially altered tree water relations through the day (Fig. 2). Over 2 days, dawn-to-dusk g was four-times greater for trees in shelters, ranging from 500 to $600 \mathrm{mmol} \cdot \mathrm{m}^{-2} \cdot \mathrm{s}^{-1}$, compared to 50 to $150 \mathrm{mmol} \cdot \mathrm{m} 2 \cdot \mathrm{s}^{-1}$ without shelters. This response was repeated in midday measurement in the field study because, in the shelters, $\mathrm{g}_{\mathrm{s}}$ was similarly high but only twice as high as trees without shelters (Table 1). Higher $\mathrm{g}_{s}$ rates appeared to moderate $t_{1}$ at levels intermediate between shelter $t_{a}$ and ambient (Fig. 2). With midday $\mathrm{t}_{1}$ measured in the field experiment, trees in shelters averaged $4 \mathrm{C}$ warmer than those outside of shelters. In the container and field study, midday $\psi$ was similar for both treatments, but predawn $\psi$ was -0.4 to -0.5 $\mathrm{MPa}$ lower for trees in shelters (Table 1). Because the container experiment was irrigated, more negative predawn $\psi$ of the sheltered trees in both experiments probably was 
due to factors other than limiting soil water.

Despite higher $g_{s}$ and $t_{1}$, transpiration normalized to unit area was 38\% less for sheltered container trees (Table 1). This difference was due to boundary layer conductance that was about two orders of magnitude lower than for trees without shelters. The small top opening limited movement of shelter air to adiabatic lift of the warmer shelter air and buffered the foliage from exposure to direct wind, as wind speeds in the shelters were $<0.1 \mathrm{~m} \cdot \mathrm{s}^{-1}$ (data not shown). This buffering restricted water vapor movement, as indicated by lower VPD levels, and effectively decoupled the stomata from the bulk air (Jarvis and McNaughton, 1986). In turn, this decoupling reduced overall transpiration from trees in the shelters. Higher shelter $t_{\mathrm{a}}$ and higher water vapor concentration often resulted in condensation on inside walls with small declines in air temperature, such as leaf shading or temporary cloud cover, during the day.

Shelters had an effect on field-grown tree growth (Table 2). Terminal shoot elongation was five-times greater for trees in shelters, with trees growing well beyond the shelter top opening. Greater shoot elongation in shelters was consistent with reports by others (Burger et al., 1992; Potter, 1988). Leaf area was also greater due to more leaves developing because of the increased number of leaf positions along the terminal shoot. Sheltered trees' trunk increment, however, was only slightly more than half of those nonsheltered. This difference may have been due in part to little trunk movement in the wind-free confined shelter (Harris et rd., 1976). Reduced increment growth was also consistent with shade acclimation. This result was verified by greater specific leaf area of foliage in the shelters-a response closely linked to shade acclimation (Bjorkman, 1982). Such a response was not unexpected,

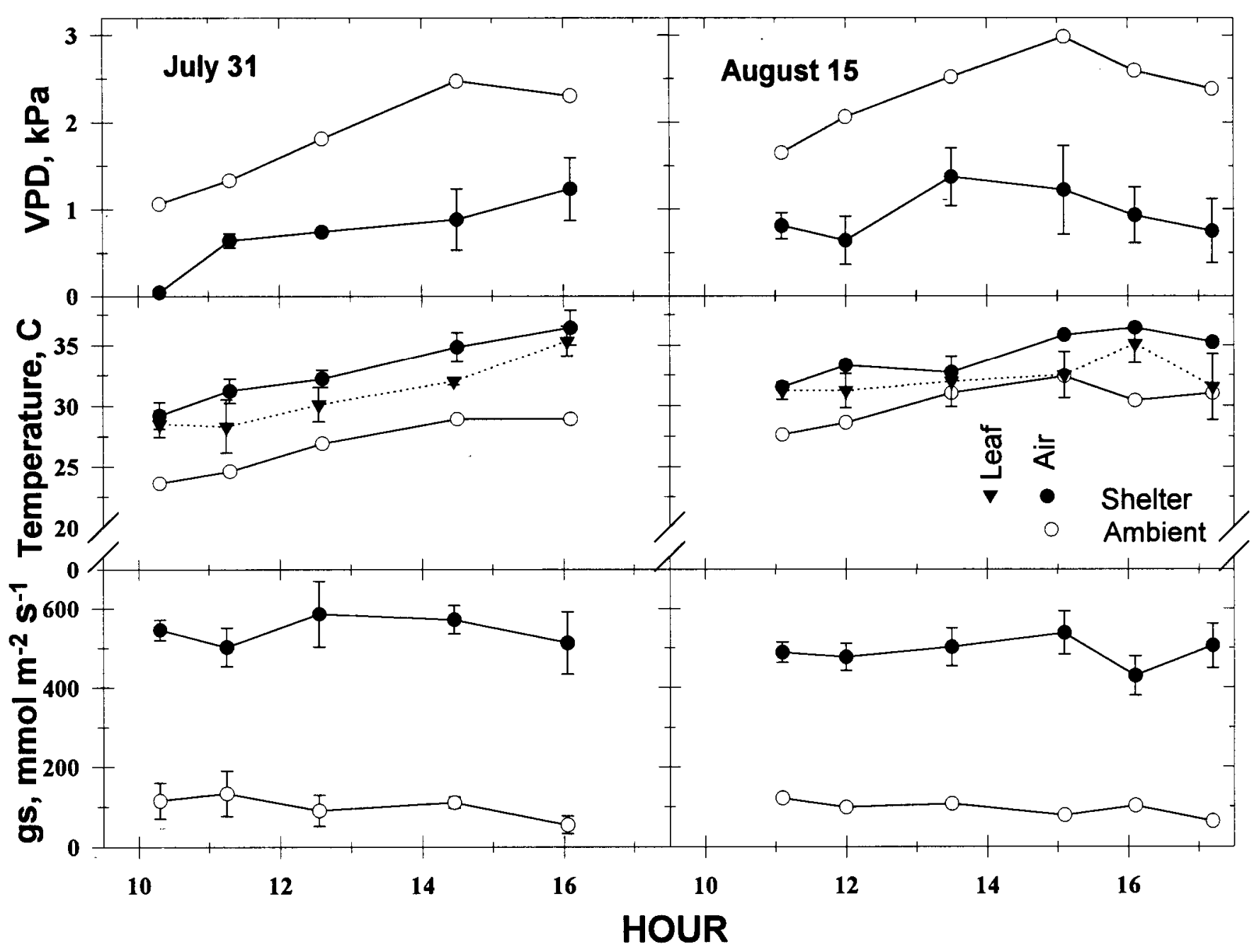

Fig. 2. Dawn-to-dusk microclimate and water relations of Kentucky coffee trees (n=3) in shelters on 31 July and 15 Aug. 1991. (a) Shelter and ambient diurnal vapor pressure deficit (VPD); (b) shelter and ambient air temperature and leaf temperature of trees in shelters; (c) stomatal conductance (g) of trees with and without shelters. Microclimate measurement in shelters and all water relations measurements include SE.

Table 1. Leaf temperatures of field-grown $(n=5)$ Kentucky coffee and tree water relations $( \pm$ se) of field-grown and container-grown $(n=3)$ Kentucky coffee with and without tree shelters. Data collected on 2 Aug. and 31 July for field and container experiments, respectively.

\begin{tabular}{|c|c|c|c|c|c|c|c|c|}
\hline \multirow[b]{3}{*}{$\underline{\text { Shelter }}$} & \multicolumn{4}{|c|}{ Field study } & \multicolumn{4}{|c|}{ Container study } \\
\hline & \multirow{2}{*}{$\begin{array}{c}\text { Leaf } \\
\text { temp }\left({ }^{\circ} \mathrm{C}\right)\end{array}$} & \multirow{2}{*}{$\begin{array}{c}\text { Stomatal } \\
\text { conductance } \\
\left(\mathrm{mmol} \cdot \mathrm{m}^{2} \cdot \mathrm{s}^{-1}\right)\end{array}$} & \multicolumn{2}{|c|}{ Water potential (MPa) } & \multirow{2}{*}{$\begin{array}{l}\text { Total daily } \\
\text { water use } \\
\left(\mathrm{g} \cdot \mathrm{m}^{-2}\right)\end{array}$} & \multirow{2}{*}{$\begin{array}{c}\text { Boundary } \\
\text { conductance } \\
\left(\mathrm{mmol} \cdot \mathrm{m}^{-2} \cdot \mathrm{s}^{-1}\right)\end{array}$} & \multicolumn{2}{|c|}{ Water potential $(\mathrm{MPa})$} \\
\hline & & & Predawn & Midday & & & Predawn & Midday \\
\hline+ & $35.7 \pm 1.6$ & $562 \pm 119$ & $-0.78 \pm 0.31$ & $-1.8 \pm 0.2$ & $800 \pm 200$ & $77 \pm 26$ & $-0.86 \pm 0.18$ & $1.59 \pm 0.12$ \\
\hline - & $31.6 \pm 0.7$ & $230 \pm 18$ & $-0.38 \pm 019$ & $-1.9 \pm 0.2$ & $1300 \pm 200$ & $6030 \pm 3960$ & $-0.39 \pm 0.09$ & $-1.54 \pm 0.16$ \\
\hline Significance & $* *$ & $* *$ & $* *$ & NS & $*$ & $* *$ & $* *$ & NS \\
\hline
\end{tabular}

${ }^{2}$ Boundary layer conductance to water vapor.

${ }_{\text {NS }, *, *}$ Nonsignificant or significant at $P \leq 0.05$ or 0.01 , respectively, using Student's $t$ test. 
Table 2. Growth responses $( \pm$ SE) of field-grown Kentucky coffee trees $(n=10)$ with and without tree shelters.

\begin{tabular}{lcccc}
\hline \hline Shelter & $\begin{array}{c}\text { Shoot } \\
\text { growth }(\mathrm{m})\end{array}$ & $\begin{array}{c}\text { Leaf } \\
\text { area }\left(\mathrm{m}^{2}\right)\end{array}$ & $\begin{array}{c}\text { Trunk } \\
\text { increment } \\
(\mathrm{mm})\end{array}$ & $\begin{array}{c}\text { Specific } \\
\text { leaf area } \\
\left(\mathrm{g}^{\circ} \mathrm{cm}^{-2}\right)\end{array}$ \\
\hline+ & $0.65 \pm 0.27$ & $4700 \pm 800$ & $3.7 \pm 1.8$ & $186 \pm 25$ \\
- & $0.13 \pm 0.06$ & $2200 \pm 300$ & $6.1 \pm 2.2$ & $90 \pm 18$ \\
Significance & $* *$ & $* *$ & $* *$ & $* *$ \\
\hline
\end{tabular}

${ }_{\text {NS, }, *}^{*}$ Nonsignificant or significant at $P \leq 0.05$ or 0.01 , respectively, using Student's $t$ test.

because shortwave radiation levels at $<25 \%$ of full sun are below light-saturated photosynthesis for many temperate tree species (Teskey and Shrestha, 1985). Another effect of shade acclimation on growth is reduced root growth (Bjorkman, 1981), which would be consistent with the limited root development observed by Burger et al. (1992) in shelter-grown trees.

Tree shelters offer several benefits for fieldproduced trees that can adapt to the shelter microclimate. For appropriate species, greater terminal shoot growth could reduce production time. Reduced transpiration in shelters could reduce water stress during field establishment and increase survival where routine irrigation is not available. The disadvantage of shelters is that greater elongation comes at the cost of trunk development and possibly root growth, due in part to shade acclimation. Shelter removal before the terminal emerges to produce sun foliage, and the consequent lack of trunk taper, would likely result in a tree without enough structural support to stand upright. This effect would render shelters unappealing to growers because larger nursery stock is graded according to trunk diameter (American Association of Nurserymen, 1986). The trees could be sheltered until there is sufficient external tree development, but benefits and costs from shelters may not warrant extending their use on one tree for longer periods.

Using lighter-colored material that allows greater light transmission might partially mitigate the shade acclimation effect. However, the lack of trunk movement could still inhibit diameter growth, and greater transmission would probably increase radiation loading in the shelters with no greater heat dissipation. High $t_{2}$ in the shelters could pose problems for species intolerant of high $t_{1}$ if they do not develop sufficient leaf area, hence transpiration, to moderate shelter temperatures. They would become subject to even higher temperatures that could limit growth. More research is needed on the effect of shelters with different transmissivities on interior microclimates, and particularly on how high $\mathrm{t}_{\mathrm{a}}$ in shelters could affect other plant processes, such as dormancy and winter hardiness.

\section{Literature Cited}

American Association of Nurserymen, 1986. American standards for nursery stock. Amer. Natl. Standards Inst. Z60: 1,32.

Bjorkman, O. 1981. Responses to different flux densities, p. 57-107. In: O. Lange, P. Nobel, C. Osmond, and H. Zeigler (eds.). Physiological plant ecology I: Responses to the physical environment. Encyclopedia of plant physiology. New series vol. 12A. Spnnger-Verlag, New York.

Burger, D.W., P. Svihra, and R. Harris. 1992 Treeshelter use in producing container-grown trees. HortScience 27:30-32.

Harris, R., A, Leiser, and W. Davis. 1976. Staking landscape trees. Univ. of California Agr. Sci. Leaflet 2583.

Jarvis, P. and K. McNaughton. 1986. Stomatal control of transpiration: Scaling up from leaf to region. Adv. Ecol. Res. 15:1-49.

McDermitt, D. 1990. Sources of error in the estimation of stomatal conductance and transpiration from porometer data, HortScience 25:15381548.

Potter, J.J. 1988. Treeshelters improve survival and increase early growth rates. J. For. 86:39-41.

Teskey, R. and R. Shrestha. 1985. A relationship between carbon dioxide, photosynthetic efficiency and shade tolerance. Physiol. Plant. 63:126-132. 